\title{
Visão dos produtores rurais, profissionais e estudantes da área agronômica, em relação à conservação do solo e da água na região de Londrina, $\mathrm{Pr}$
}

\section{Vision of the farmers, professional and students of the agronomic area in respect of soil and water conservation in Londrina, $\mathrm{Pr}$}

\author{
João Tavares Filho' ${ }^{1 *}$; Mariana Rinschede ${ }^{2}$
}

\section{Resumo}

\begin{abstract}
A degradação ambiental, decorrente do mau uso dos recursos naturais e de técnicas de produção inadequadas, é um problema atual e vem sendo tema de debates pela sociedade civil, governo e iniciativa privada, que buscam formular soluções e reunir esforços que diminuam o impacto e desacelerem esse processo. Porém, ao longo do tempo a exploração mais intensificada buscando sempre altas produções e grandes retornos econômicos, muitas vezes indo na contra-mão da preservação e conservação dos recursos ambientais. Dessa forma, o presente trabalho foi desenvolvido com o objetivo de levantar dados sobre o interesse pela conservação do solo e água, no meio rural, técnico e educacional. De acordo com os resultados obtidos, conclui-se que $74 \%$ dos produtores rurais entrevistados consideram necessário utilizar práticas conservacionistas na propriedade e $26 \%$ não vêem essa necessidade. Entretanto, somente 31,6\% fazem uso de práticas de conservação do solo por opção pessoal, contra $68,5 \%$ que utilizam somente mata ciliar e reflorestamento por imposição da lei. Em relação aos profissionais da área de Agronomia, $100 \%$ dos que responderam o questionário vêem necessidade de se utilizar práticas de conservação do solo e da água na atividade agrícola, sendo consideradas mais importantes pelos profissionais: mata ciliar (24\%), plantio direto (15\%) e terraço agrícola (6\%), entretanto, $39 \%$ dos profissionais não vêem necessidade em se utilizar terraço agrícola em áreas com plantio direto. No caso dos alunos do curso de Agronomia da Universidade Estadual de Londrina, somente 50\% estão no curso por opção pessoal e $50 \%$ fazem o curso por influência dos pais (filhos de agricultores) ou por outras razões que não a atração pela profissão; e $80 \%$ dos alunos cursariam a disciplina de conservação do solo e da água, independente de ser obrigatória ou optativa e $20 \%$ só cursam ma mesma por serem obrigados.
\end{abstract}

Palavras-chave: Práticas conservacionistas, extensão rural, meio ambiente, degradação ambiental

\begin{abstract}
The ambient degradation due to bad use of the natural resources and the inadequate techniques of production is a current problem and is being subject of debates among the civil society, government and private initiative that search to formulate solutions and to congregate efforts to diminish the impact and decelerate this process. However, throughout the time the intensified exploration aiming always high productions and great economic returns goes many times in the against-hand of the preservation and conservation of the environmental resources. So, this work was developed with the aim of knowing the interest of farmers, students and Agronomic professionals for the conservation of soil and water. It was concluded that $74 \%$ of the interviewed agricultural producers consider necessary to use conservationist's practices in the property and $26 \%$ do not see this necessity. However, $31.6 \%$ only make use of conservation
\end{abstract}

1 Professor do Dep. de Agronomia, Universidade Estadual de Londrina, C. P: 6001, CEP: 86.051-990, Londrina, PR; E-mail: tavares@uel.br

2 Acadêmico de Agronomia, Universidade Estadual de Londrina.

* Autor para correspondência 
practices for personal option, against $68.5 \%$ that only use riparian forest and reforestation for imposition of the law. In relation to the professionals of the area of Agronomy, $100 \%$ of them see necessity in using conservation practices in the agricultural activity, and consider more important: riparian forest $(24 \%)$, no tillage (15\%) and agricultural terrace (6\%); however, $39 \%$ of the professionals do not see necessity in using agricultural terrace in areas with no tillage. The students of the course of Agronomy of the State University of Londrina, $50 \%$ only are in the course for personal option and $50 \%$ attend influence of the parents or for other reasons that not it attraction for the profession; and $80 \%$ of the students would attend a course on soil an water conservation and $20 \%$ would do it if obliged.

Key words: Conservation practices, agricultural extension, environment, ambient degradation

A degradação ambiental, decorrente do mau uso dos recursos naturais e de técnicas de produção inadequadas, é um problema atual e vem sendo tema de debates pela sociedade civil, governo e iniciativa privada, que buscam formular soluções e reunir esforços que diminuam o impacto e desacelerem esse processo.

Dois desses recursos ganham atenção especial em campanhas de preservação; o solo e a água. Esta importância justifica-se por serem componentes fundamentais do ecossistema terrestre, sendo essenciais para a existência de vida (animal e vegetal uma vez que fornecem nutrientes vitais a todas as espécies) e serem determinantes para a produção de alimentos, sendo a agropecuária o ramo que mais utiliza diretamente esses recursos, explorando-os para retirada de seus produtos comerciais. Apesar disso, hoje se observa a degradação desses recursos devido ao uso inadequado tanto nas zonas rurais quanto nas zonas urbanas. Segundo M. A. F. Gomes (apud EMBRAPA, 2008) ocorre uma perda de solo no País em torno de 1 bilhão de toneladas $a o^{-1} \mathrm{e}$ uma perda mundial de 23 bilhões de toneladas ano ${ }^{-1}$, e, além disso, há a contaminação das águas superficiais e subterrâneas com a liberação de lixos sólidos e líquidos nos cursos dos rios, nascentes e mananciais e aumento no índice de turbidez e diminuição dos leitos devido à enxurradas que também geram enchentes causando graves conseqüências socioeconômicas.

No Brasil existe a Lei de $n^{\circ} 7876$, de novembro de 1989 que institui o Dia Nacional da Conservação do Solo, comemorado em todo País no dia 15 de
Abril, além disso, um substitutivo ao projeto de Lei $\mathrm{n}^{\circ} 1.301$, de junho de 2007 altera a Lei $\mathrm{n}^{\circ} 8.171$, de 17 de janeiro de 1991, sobre o uso e a conservação do solo e da água no meio rural em todo território nacional (COLATTO, 2007), uma vez que a conservação de solo e água envolve um conjunto de medidas que objetivam manter ou recuperar as condições físicas, químicas e biológicas do solo estabelecendo critérios para o uso e manejo das terras, de forma a não comprometer sua capacidade produtiva (BAHIA et al., 1992). Essas medidas visam proteger o solo, evitando problemas comuns como erosão e a compactação, além de minimizar efeitos provocados pelas chuvas e pelo uso do homem.

Dentro desse contexto, a conservação do solo passa a ter um conceito social que implica determinar e colocar em prática como o homem pode satisfazer suas necessidades físicas, econômicas e ecológicas a partir do solo, sem danificar sua capacidade de continuar a satisfazer-lhe as necessidades do futuro. Segundo Cormack Whitelaw (apud BAHIA et al., 1992), sem um fornecimento regular e digno de confiança de alimentos e outros produtos agrícolas e água, toda nossa estrutura econômica entrará em colapso, e nenhum sistema de controle financeiro, contabilidade, cálculos, compras e vendas poderá conter esse colapso.

Porém, ao longo do tempo a exploração agrícola do solo e água passou a ser mais intensificada objetivando sempre altas produções com grandes retornos econômicos, indo muitas vezes na contra-mão da preservação e conservação dos 
recursos ambientais em função do uso inadequado pelo ser humano, como o uso fora da aptidão agrícola, intensa mecanização, desmatamentos indiscriminados, entre outros. Os riscos eminentes de alcançar o ponto crítico de degradação ambiental e conseqüentemente econômica e social exigiram dos governos e profissionais da área a busca de soluções e estratégias de melhoria dos processos produtivos, visando a sustentabilidade da agricultura ao longo prazo.

No Brasil vários governos estaduais buscam auxílio financeiro em bancos mundiais com o propósito de implementar programas ou projetos que procuram conciliar conservação ambiental com aumento de produção agropecuária. Nesse aspecto o Paraná conseguiu destaque nacional e internacional através do Programa de Desenvolvimento do Paraná, conhecido como Paraná Rural, e seus sub programas, ou seja, o programa de manejo das águas, conservação do solo e controle da poluição em microbacias hidrográficas. O programa foi reconhecido pela FAO (Food and Agriculture Organization) como um dos mais eficazes esforços direcionados a sustentabilidade e à competitividade da agricultura em zonas tropicais e sub tropicais (PARANÁ, 1989) e, no ano de 1999, durante a X Conferência da Organização Internacional de Conservação do Solo realizada na Universidade de Purdue (Indiana, USA), foi destacado como modelo de estratégia para a conservação e preservação dos recursos naturais (INTERNATIONAL SOIL CONSERVATION ORGANIZATION, 1999).

Este programa atingiu resultados surpreendentes como: redução significativa no índice médio de turbidez das águas, aumento da produtividade das culturas devido ao aumento nos níveis de potássio, carbono e fósforo nos solos trabalhados, altos índices de adoção das práticas conservacionistas recomendadas, principalmente entre produtores de pequenas (até 50 ha) e médios (51 a 100 ha) propriedades devido a tais práticas terem custo compatível com a escala de produção desse segmento de produtores (FLEISCHFRESSER, 1999). Um dos fatores de sucesso deve-se ao fato de que durante sua implementação, o programa procurou levar em conta a dinâmica organizacional do sistema e os fatores agroecológicos e sócio-econômicos que influenciavam a lógica dos produtores de cada região em aceitar ou rejeitar as inovações técnicas. Isso, aliado à ação direta das organizações de extensão e pesquisa de cada local, permitiu encontrar soluções estratégicas e tecnológicas de minimização dos impactos existentes naquela determinada região trazendo melhorias econômicas, sociais e ambientais preservando as particularidades locais, favorecendo mudança no comportamento e forma de pensar dos agentes envolvidos (PARANÁ, 1989; FLEISCHFRESSER, 1999). Os resultados alcançados com Programa Paraná Rural influenciaram os projetos posteriores formulados e negociados pelo governo estadual paranaense junto aos organismos internacionais (GODOY, 2006).

Essa experiência mostrou a necessidade de integração entre agricultores, entidades extensionistas, de pesquisas, universidades e governo na criação de políticas públicas que darão resultados concretos e reais, buscando equilíbrio entre os fatores econômicos, sociais e ambientais, uma vez que estas entidades observam os problemas no campo e pesquisam soluções práticas para os mesmos, influenciando assim nas políticas de governo que poderão ser implantadas para benefício comum. Entretanto(,) para que o conhecimento chegue ao produtor rural, é fundamental conhecer qual o grau de abrangência do assunto em pauta e qual o melhor meio de comunicação para atingir e despertar o interesse do mesmo.

Dessa forma, presente trabalho foi desenvolvido com o objetivo de levantar dados a cerca do interesse pela conservação do solo e água, no meio rural, técnico e educacional com vistas fornecer subsídios para desenvolvimentos de projetos conservacionistas que sejam aceitos na região estudada.

O levantamento de dados foi feito com produtores rurais e profissionais (técnicos e 
engenheiros agrônomos) da região de Londrina, Cambé, Rolândia, Ibiporã e Sertanópolis além dos alunos da Universidade Estadual de Londrina matriculados em todos os anos $\left(1^{\circ}, 2^{\circ}, 3^{\circ}, 4^{\circ}\right.$ e $\left.5^{\circ}\right)$ do curso de Agronomia. Para cada uma dessas categorias, foi elaborado um questionário (Quadro 1), com perguntas objetivas, elaboradas a partir da orientação obtida com um Profissional da área de Psicologia.

Os questionários (200 questionários por categoria), foram distribuídos em revendas de produtos agropecuários, cooperativas agrícolas e via DCE / Agronomia UEL. Nos questionários não havia como fazer identificação (nome, endereço, telefone, etc.) daqueles que o respondiam, buscando total imparcialidade para a avaliação dos resultados

Dos questionários distribuídos, conseguiu-se a participação de 73 produtores rurais, 45 profissionais da área de Agronomia e 100 alunos do curso de Graduação em Agronomia da Universidade Estadual de Londrina. Esses resultados foram analisados em separados de acordo com a categoria, ou seja:

a) PRODUTORES RURAIS: os resultados obtidos para a categoria dos produtores rurais, são apresentados no Quadro 1. Verifica-se que 54.7\% possuem o ensino fundamental e a maioria $(55 \%)$ não é cooperado. Em relação à conservação do solo e água, $74 \%$ acha necessário utilizar práticas conservacionistas na propriedade contra $26 \%$ que não vêem essa necessidade. Acredita-se que esse último grupo considera um custo elevado para implantação das práticas, sem posterior retorno em produção / lucratividade.

Em relação àqueles que vêem necessidade em utilizar práticas de conservação de solo e água, somente $31,6 \%$ o fazem por opção pessoal, sendo as mais citadas o terraço agrícola (13\%), o plantio direto $(9,3 \%)$ e a cobertura do solo com palhada da cultura anterior $(9,3 \%)$ contra $68,5 \%$ que utilizam as práticas por imposição da lei, sendo as mais usadas, nesse caso, a mata ciliar e o reflorestamento em áreas de preservação permanente fiscalizadas, que se não estiverem de acordo com a lei implicará em multa ao responsável.

Em relação à necessidade em utilizar terraço agrícola em área com plantio direto, a grande maioria $(87,7 \%)$ não vê necessidade e somente $12,3 \%$ acreditam nos benefícios de se fazer plantio direto e terraço agrícola. Esse fato pode estar relacionado ao reaparecimento de erosão em áreas agrícolas onde essa tinha sido quase que eliminada.

Essas respostas sugerem que a não utilização intensiva das práticas de conservação do solo e água pode estar relacionada com uma certa deficiência na fiscalização pelos órgãos competentes. Observa-se também que apesar de todos os programas feitos pelo governo e entidades de extensão poucos produtores na região utilizam-se das demais técnicas de conservação como terraceamento e / ou coberturas vegetais vivas ou mortas, mesmo estando localizados em um estado considerado como referencial em práticas conservacionistas de solo e água.

Portanto, a questão é saber se esses produtores não estão recebendo a devida assistência ou se eles não sabem qual a responsabilidade que lhes cabe perante a sociedade em preservar os recursos naturais que devem ser utilizados como patrimônio da coletividade, ou se eles não possuem condições financeiras para a realização da conservação do solo e água, ou ainda se falta acesso à informação. Ainda, aqueles produtores que mais usam práticas relataram que a forma como entraram em conhecimento com as técnicas foi, em primeiro lugar, através dos técnicos das cooperativas e vizinhos (23 e 22\%, respectivamente), seguido por cursos e palestras (15\%). A revenda / assistência técnica, revistas e jornais foram pouco citados enquanto a internet não foi citada por nenhum. Esse resultado sugere que a melhor forma de atingir os produtores é indo ao encontro deles com as orientações e procurando mostrar exemplos práticos dos resultados. 


\begin{tabular}{|c|c|c|c|}
\hline \multicolumn{4}{|c|}{ PRODUTORES RURAIS } \\
\hline \multicolumn{2}{|c|}{ Total que responderam o questionário } & 73 & $100,0(\%)$ \\
\hline \multirow{5}{*}{ Grau de Escolaridade } & Fundamental Incompleto & 16 & $21,9 \%$ \\
\hline & Fundamental Completo & 24 & $32,8 \%$ \\
\hline & Ensino Médio Incompleto & 13 & $17,8 \%$ \\
\hline & Ensino Médio Completo & 17 & $23,3 \%$ \\
\hline & Superior & 3 & $4,2 \%$ \\
\hline \multirow{2}{*}{ É Cooperado? } & $\operatorname{Sim}$ & 33 & $45 \%$ \\
\hline & Não & 40 & $55 \%$ \\
\hline \multirow{2}{*}{$\begin{array}{l}\text { O Senhor vê necessidade em } \\
\text { utilizar práticas de conservação } \\
\text { de solo e água? }\end{array}$} & Sim & 54 & $74,0 \%$ \\
\hline & Não & 19 & $26,0 \%$ \\
\hline \multirow{5}{*}{$\begin{array}{c}\text { Para os que responderam SIM } \\
\text { (54 produtores) na questão } \\
\text { anterior: }\end{array}$} & $\begin{array}{l}\text { Práticas citadas, utilizadas } \\
\text { por opção pessoal: }\end{array}$ & & \\
\hline & - Terraço (“curva de nível”) & 7 & $13,0 \%$ \\
\hline & - Cobertura Vegetal & 5 & $9,3 \%$ \\
\hline & - Plantio Direto & 5 & $9,3 \%$ \\
\hline & $\begin{array}{c}\text { Práticas citadas utilizadas por } \\
\text { imposição da Lei: } \\
\text { - Mata Ciliar e } \\
\text { Reflorestamento }\end{array}$ & 37 & $68,5 \%$ \\
\hline \multirow{2}{*}{$\begin{array}{c}\text { Independente do declive e } \\
\text { pluviometria, o Senhor vê } \\
\text { necessidade em utilizar terraço } \\
\text { agrícola em área com plantio } \\
\text { direto? }\end{array}$} & Sim & 9 & $12,3 \%$ \\
\hline & Não & 64 & $87,7 \%$ \\
\hline \multirow{5}{*}{$\begin{array}{c}\text { Como teve conhecimento dessa } \\
\text { (as) prática (as) e das exigências } \\
\text { da Lei? }\end{array}$} & Revista/jornal; & 5 & $6,8 \%$ \\
\hline & Técnico da cooperativa; & 23 & $31,5 \%$ \\
\hline & Vizinhos; & 22 & $30,2 \%$ \\
\hline & $\begin{array}{l}\text { Técnico da assistência/ } \\
\text { revenda }\end{array}$ & 8 & $11,0 \%$ \\
\hline & Cursos/ palestras; & 15 & $20,5 \%$ \\
\hline
\end{tabular}

Quadro 1. Respostas obtidas a partir dos questionários respondidos pelos produtores rurais.

b) PROFISSIONAIS DA ÁREA DE engenheiros agrônomos e 11\% técnicos agrícolas e AGRONOMIA: os resultados obtidos para a 100\% dos que responderam mo questionário vêem categoria dos profissionais da área de agronomia são necessidade em se utilizar práticas de conservação apresentados no Quadro 2. Verifica-se que 89\% são do solo e água na atividade agrícola. 


\section{PROFISSIONAIS DA ÁREA DE AGRONOMIA}

\begin{tabular}{|c|c|c|c|}
\hline \multicolumn{2}{|c|}{$\begin{array}{l}\text { Total que responderam o questionário (considerando os } \\
\text { profissionais de cooperativas, órgãos públicos, revendas e } \\
\text { assistências técnicas) }\end{array}$} & 45 & $100,0 \%$ \\
\hline Grau de Escolaridade & $\begin{array}{l}\text { Engenheiro Agrônomo } \\
\text { Técnico Agrícola }\end{array}$ & $\begin{array}{l}45 \\
05\end{array}$ & $\begin{array}{l}88,9 \% \\
11,1 \%\end{array}$ \\
\hline $\begin{array}{l}\text { O Senhor vê necessidade em } \\
\text { utilizar práticas de conservação de } \\
\text { solo e água? }\end{array}$ & $\begin{array}{l}\text { Sim } \\
\text { Não }\end{array}$ & $\begin{array}{l}45 \\
00\end{array}$ & $100 \%$ \\
\hline $\begin{array}{l}\text { Para os que responderam SIM } \\
\text { (45 produtores) na questão } \\
\text { anterior: }\end{array}$ & $\begin{array}{c}\text { Qual prática considera mais } \\
\text { importante: } \\
\text { - Mata ciliar } \\
\text { - Plantio direto } \\
\text { Terraço (“curva de nível”) } \\
\text { Práticas citadas utilizadas por } \\
\text { imposição da Lei: } \\
\text { - Mata Ciliar e } \\
\text { Reflorestamento }\end{array}$ & $\begin{array}{l}24 \\
15 \\
06 \\
\\
37\end{array}$ & $\begin{array}{l}53,3 \% \\
33,3 \% \\
13,3 \% \\
68,5(\%)\end{array}$ \\
\hline $\begin{array}{c}\text { Independente do declive e } \\
\text { pluviometria, o Senhor vê } \\
\text { necessidade em utilizar terraço } \\
\text { agrícola em área com plantio } \\
\text { direto? }\end{array}$ & $\begin{array}{l}\text { Sim } \\
\text { Não }\end{array}$ & $\begin{array}{l}06 \\
39\end{array}$ & $\begin{array}{l}13,3 \% \\
86,7 \%\end{array}$ \\
\hline $\begin{array}{l}\text { Como procura se atualizar em } \\
\text { relação à conservação do solo e } \\
\text { água? }\end{array}$ & $\begin{array}{l}\text { Revista especializada; } \\
\text { Internet; } \\
\text { Programas de rádio e TV; } \\
\text { Cursos / Palestras; } \\
\text { Dia de Campo. }\end{array}$ & $\begin{array}{l}03 \\
05 \\
05 \\
05 \\
27\end{array}$ & $\begin{array}{l}6,70 \% \\
22,2 \% \\
22,2 \% \\
22,2 \% \\
60,0 \%\end{array}$ \\
\hline
\end{tabular}

Quadro 2. Respostas obtidas a partir dos questionários respondidos pelos profissionais da área de agronomia.

Em relação às práticas consideradas importantes pelos técnicos, somente três foram citadas, sendo mata ciliar $(24 \%)$, plantio direto $(15 \%)$ e terraço agrícola (6\%). Essa maior porcentagem para a mata ciliar se deve, provavelmente, ao conhecimento da Lei e que as áreas de preservação são fiscalizadas. Embora ainda lembrado pelos técnicos, o terraço agrícola parece não ser mais considerado importante na contenção das enxurradas e controle de erosão e essa hipótese parece ser confirmada por 39\% dos profissionais que indicaram não ver necessidade em utilizar terraço agrícola em áreas de plantio direto, independente do declive e pluviometria.

Em relação à forma como os profissionais procuram se atualizar, os dias de campo estão em grande destaque com $60 \%$ das respostas. Cursos e palestras, revistas especializadas e Internet foram pouco citados. Esse resultado sugere que a melhor forma de atingir esses profissionais é através de dias de campo onde podem ser mostrados resultados de pesquisa e inovações técnicas.

c) ALUNOS: os resultados obtidos para a categoria dos Alunos em Agronomia da Universidade Estadual de Londrina são apresentados no Quadro 3. Do total entrevistado $72 \%$ são filhos de produtores ou pais que trabalham na área rural. Desse total, $10 \%$ estava iniciando o urso, $50 \%$ estava cursando o $2^{\circ}$ e $3^{\circ}$ ano e $40 \%$ estavam cursando o $4^{\circ}$ e $5^{\circ}$ ano. 
ALUNOS DO CURSO DE AGRONOMIA DA UEL

\begin{tabular}{c|c|c|c}
\hline \multicolumn{2}{c|}{ Total que responderam o questionário } & $\mathbf{1 0 0}$ & $\mathbf{1 0 0 , 0} \%$ \\
\hline & $1^{\text {o }}$ & 10 & $10 \%$ \\
\cline { 2 - 4 } Qual ano esta cursando ? & $2^{\text {o }}$ & 25 & $25 \%$ \\
& $3^{\circ}$ & 25 & $25 \%$ \\
\hline Se a disciplina de conservação do & $4^{\text {o }}$ & 20 & $20 \%$ \\
solo e água fosse optativa, você a & 5 & 20 & $80 \%$ \\
faria ? & Sim & 80 & $20 \%$ \\
\hline \multirow{2}{*}{ Qual a importância da conservação } & Não & 20 & $40 \%$ \\
do solo e água em sua futura & & 40 & $40 \%$ \\
atividade ? & Muita & 40 & $15 \%$ \\
\hline
\end{tabular}

Quadro 3. Respostas obtidas a partir dos questionários respondidos pelos alunos do curso de agronomia da Universidade Estadual de Londrina (UEL).

Por outro lado, se a disciplina de conservação de solos e água fosse optativa $80 \%$ dos alunos a cursariam e $20 \%$ não teriam interesse pela mesma, percentagem essa, igual aos $20 \%$ que fazem o curso não por opção pessoal. Além disso, esses resultados estão em acordo com a importância dada pelos alunos em relação à conservação do solo após sua formatura e importância dada pelos profissionais (Quadro 2). Portanto, parece existir interesse por parte dos alunos em relação à conservação do solo e água - preservação ambiental, indicando uma boa conscientização e preocupação em preservar o solo e a água.

De acordo com os resultados obtidos, conclui-se que:

- $74 \%$ dos produtores rurais entrevistados consideram necessário utilizar práticas conservacionistas na propriedade contra $26 \%$ que não vêem essa necessidade;

- a (grande) maioria dos produtores rurais não vê necessidade do uso do terraço agrícola em áreas de plantio direto, e somente 12,3\% acreditam nos benefícios de se fazer plantio direto e terraço agrícola;
- $100 \%$ dos profissionais da área de agronomia, vêem necessidade de se utilizar práticas de conservação do solo e água na atividade agrícola, sendo consideradas mais importantes pelos profissionais a mata ciliar (24\%), plantio direto (15\%) e terraço agrícola (6\%); entretanto;

- 39\% dos profissionais da área de agronomia, não vêem necessidade de se utilizar terraço agrícola em áreas com plantio direto;

- $80 \%$ dos alunos do curso de agronomia da Universidade Estadual de Londrina cursariam a disciplina de conservação do solo e água, independente de ser obrigatória ou optativa e $20 \%$ só cursam a mesma por serem obrigados.

\section{Referências}

BAHIA, V. G.; CURI, N.; CARMO, D. N.; MARQUES, J. J. S. M. Fundamentos de erosão do solo (tipos, formas, mecanismos, fatores determinantes e controle). Informe Agropecuário, Belo Horizonte, v. 16, n. 176, p. 25-31. 1992.

COLATTO, V. Projeto de lei que dispõe sobre o uso e a conservação do solo e da água no meio rural. 2007. 
Disponível em: <http://www.camara.gov.br/sileg/ MostrarIntegra.asp?CodTeor $=468753>$. Acesso em: 10 abr. 2008.

EMPRESA BRASILEIRA DE PESQUISA AGROPECUÁRIA - EMBRAPA. Projetos para conservação de solo dependem de conscientização para serem valorizados. Disponível em: <http://www.cnpma. embrapa.br/nova/mostra2.php3?id=275>. Acesso em: 10 abr. 2008

FLEISCHFRESSER, V. Políticas públicas e a formação de redes conservacionistas em microbacias hidrográficas: o exemplo do Paraná Rural. Revista Paranaense de Desenvolvimento, Curitiba, n. 95, p. 61-77, jan./abr. 1999.
GODOY, A. M. G. Aprendizagem coletiva e avanços tecnológicos e ambientais na agricultura paranaense. Revista Paranaense de Desenvolvimento, Curitiba, $\mathrm{n}$. 110, p. 69-90, jan./jun. 2006.

INTERNATIONAL SOIL CONSERVATION ORGANIZATION - ISCO. Sustaining the global farm. Strategic issues, principles and approaches. In: INTERNATIONAL SOIL CONSERVATION ORGANIZATION CONFERENCE, 10., 1999. Indiana. Proceedings... Indiana: Purdue University, West Lafayette,1999. p. 42.

PARANÁ. Secretaria de Estado da Agricultura e do Abastecimento. Paraná Rural. subprograma de manejo e conservação do solo. Curitiba: SEAAP, 1989. 306p. 